\title{
Effect of Soy Milk and Bifidobacterium-Fermented Soy Milk on Plasma and Liver Lipids in Ovariectomized Syrian Hamsters
}

\author{
Hiroko KikUChI-HAYAKAWA, Norie OnODERA-MasUoKa, Mitsuyoshi Kano, \\ Satoshi MATSUBARA, Emi YASUDA and Fumiyasu IsHIKAWA \\ Yakult Central Institute for Microbiological Research, \\ Yaho 1796, Kunitachi-shi, Tokyo, 186-8650, Japan
}

(Received September 30, 1999)

\begin{abstract}
Summary The effects of soy milk and fermented soy milk on lipid metabolism were studied in ovariectomized Syrian hamsters. Five mo-old Syrian hamsters were randomly assigned to four treatment groups: ovariectomized (OVX) + control diet (OVX-C); OVX+soy milk diet (OVX-SM); OVX+fermented soy milk diet (OVX-FSM); and sham-operated+control diet (Sham-C). The hamsters were fed on these diets for $4 \mathrm{wk}$. The atherogenic index value of the OVX-FSM group was lower than that of the OVX-C group. The plasma triglyceride level of the OVX-FSM group was significantly lower than that of the OVX-C group. The liver total cholesterol contents in the OVX-SM and OVX-FSM groups were significantly lower than that in the OVX-C group. Thus, these results demonstrate that bifidobacteriumfermented soy milk had a hypolipidemic effect in ovariectomized hamsters.

Key Words ovariectomy, isoflavones, fermented soy milk, lipid metabolism
\end{abstract}

Postmenopausal women have a risk of coronary heart disease, which has been found to be at least partially attributable to an increase in total cholesterol, LDL-cholesterol and triglycerides, a reduction in $\mathrm{HDL}_{2}^{-}$ cholesterol (1). Estrogen reduces the risk of cardiovascular diseases (2). Genistein, an isoflavone abundant in soy products; has weak estrogenic activities, and functions as both an estrogen agonist and antagonist in vitro (3). Genistein exists in nature almost exclusively as $\beta$-glucoside (4). Bifidobacterium breve strain Yakult causes the release of aglycones from isoflavone glucosides in soy milk by $\beta$-glucosidase (5). It has also been reported that genistein is absorbed more rapidly than its glycoside (6). The soy milk fermented by Bifidobacterium breve strain Yakult prevented the cholesterol elevation induced in rat ovarian hormone deficiency (7) as well as that in growing male hamsters fed a high fat cholesterol enriched diet (8). Hamsters are known to resemble humans in respect to dietary influences on lipid metabolism $(9-10)$. The ovariectomized hamster is a useful animal model for postmenopousal hypercholesterolemia (11). There are no reports on the effect of soy products on lipid metabolism in ovariectomized hamsters.

The purpose of this study was to evaluate the effects of bifidobacterium-fermented soy milk on the lipid metabolism in ovariectomized estrogen-deficient hamsters.

\section{Materials and methods}

Preparation of fermented soy milk. Crude soy milk from Shikokukakouki Co. Ltd. (Tokushima, Japan) was used as the starting material for fermented soy milk. Bifidobacterium breve strain Yakult was obtained from the collection of the Culture Collection Research Laboratory of Yakult Central Institute for Micro- biological Research (Tokyo, Japan). A seed culture prepared anaerobically in the soy milk was freshly added to the soy milk at a $1: 100(\%)$ inoculation ratio and fermented statically at $37^{\circ} \mathrm{C}$ for $30 \mathrm{~h}$. The titratable acidity, $\mathrm{pH}$, and viable cell counts of the fermented soy milk were $0.813 \%, 4.61$ and $2.08 \times 10^{9}$ colony-forming units/mL, respectively. The original soy milk and fermented soy milk were freeze-dried and milled until the products passed through a $0.84 \mathrm{~mm}$ sieve (20 mesh). The crude protein, crude fat, ash and dietary fiber content levels in the freeze-dried soy milk were 45.0, 24.5, 5.5 , and $0 \%$, respectively. That of carbohydrate was estimated as $25.0 \%$. These composition were unaffected by the fermentation process $(8)$.

Animals and diets. Five-mo-old female hamsters (Japan S.L.C. Co., Shizuoka, Japan) were housed individually in stainless-steel wire-bottomed cages in a room with controlled lighting (lights on 08:30-20:30), temperature $\left(24 \pm 2^{\circ} \mathrm{C}\right)$, and humidity $(60 \pm 5 \%)$. The animals were given free access to a stock diet (MF; Oriental Yeast, Tokyo) for $7 \mathrm{~d}$. After the menstruation of all hamsters had been confirmed by the observation of epithelial cells in the vagina for $6 \mathrm{~d}, 17$ hamsters were ovariectomized and four had a sham operation. After a seven-day recovery from the operation, the absence of menstruation in the ovariectomized hamsters and the regular menstruation of the sham-operated hamsters were confirmed for $6 \mathrm{~d}$. The ovariectomized hamsters were separated into three groups of six or five animals each, with similar mean body weights. The ovariectomized hamsters were assigned to control (OVX-C), soy milk (OVX-SM) and fermented soy milk (OVX-FSM) groups. The sham-operated hamsters were fed a control diet (sham-C). The compositions of the experimental 
diets are shown in Table 1. Protein and lipid in soy milk and FSM were replaced by casein and corn oil in the control, respectively. Carbohydrate, ash and the other component in the soy milk and fermented soy milk were replaced by sucrose in the control. The animals were given free access to the test diets and water for $28 \mathrm{~d}$. Body weight was recorded once a week, and food consumption was recorded every 2 or $3 \mathrm{~d}$. After $23 \mathrm{~d}$ of the experimental diet, feces were collected for $3 \mathrm{~d}$. At the end of the $4 \mathrm{wk}$, the experimental diet period, the hamsters were anesthetized with an intraperitoneal injection of pentobarbital sodium (Nembutal ${ }^{\circledR}$, Abbot Laboratories, Chicago, IL, USA), $25 \mathrm{mg} / \mathrm{kg}$ body weight. Food was withheld for $4 \mathrm{~h}$ before death. Blood was collected from the aorta ventralis into tubes containing EDTA and then separated by centrifugation at $2,000 \times g$ for $15 \mathrm{~min}$ at $4^{\circ} \mathrm{C}$. The liver was perfused in situ with saline $(8.5 \mathrm{~g} \mathrm{NaCl} / \mathrm{L})$, removed, weighed and then kept in a plastic bag at $-20^{\circ} \mathrm{C}$. The uterus was removed and weighed. The animals were maintained in accordance with the guidelines of the Ethical Committee for Animal Experiments of Yakult Central Institute.

Analyses

Diet. Crude protein, diethylether extract (crude lipid), and crude ash analyses of unfermented milk were carried out by the method of the Association of Official Analytical Chemists (12).

Plasma and liver lipids. Total cholesterol, HDL-cholesterol and triglyceride in plasma were measured enzy-

Table 1. Compositions of the experimental diets (\%).

\begin{tabular}{lcccc}
\hline & OVX-C & OVX-SM & OVX-FSM & Sham-C \\
\hline Soy milk & 0 & 30 & 0 & 0 \\
Fermented soy milk & 0 & 0 & 30 & 0 \\
Casein & 25 & 11.5 & 11.5 & 25 \\
Corn oil & 10 & 2.65 & 2.65 & 10 \\
Lard & 7 & 7 & 7 & 7 \\
Cellulose & 5 & 5 & 5 & 5 \\
Vitamine mixture* & 1 & 1 & 1 & 1 \\
Mineral mixture* & 3.5 & 3.5 & 3.5 & 3.5 \\
Choline bitartrate & 0.2 & 0.2 & 0.2 & 0.2 \\
Sucrose & 15 & 5.85 & 5.85 & 15 \\
$\alpha$-corn starch & 33.3 & 33.3 & 33.3 & 33.3 \\
\hline
\end{tabular}

* The vitamin and mineral mixtures were those of AIN-76 (31). matically with commercial kits (Determiner TC555, Kyowa Medics, Tokyo; HDL cholesterol Wako, Wako Pure Chemical Industries, Tokyo; and Triglyceride G test Wako, Wako Pure Chemical Industries). Liver lipids were extracted by the method of Folch et al. (13) and redissolved in ethanol. The liver total cholesterol and triglyceride concentrations were measured enzymatically as described above.

Fecal bile acid. The fecal bile acid was determined as described by Kikuchi-Hayakawa et al. (8).

Statistical analysis. The results were expressed as means and SD. The means were compared using STATISTICA software (StatSoft, Inc., Oklahoma, USA), by ANOVA and subsequent Tukey's HSD comparisons after logarithmic transformation to stabilize the variance, if the variance was significant (14). The difference was considered to be statistically significant when $p$ was less than 0.05 .

\section{Results and Discussion}

No significant differences in the final body weight, food intake or liver weight were detected (Table 2). It has been reported that ovariectomy increases food intake in rats (15) but not in hamsters (16). The uterus weight in the OVX-C group was $27 \%$ of that in the sham-C group. The uterus weights in the OVX-SM and OVX-FSM groups were the same as that in the OVX-C group. Soy milk and fermented soy milk did not affect the uterus weight in the ovariectomied hamsters, as was reported for ovariectomized rats (7).

The plasma total cholesterol was affected by neither the diet nor operation (Table 3). The atherogenic index value for the OVX-FSM group was lower than that for the OVX-C group. The plasma triglyceride level of the OVX-FSM group was significantly lower than that of the OVX-C group. The plasma triglyceride and atherogenic index value in the OVX-SM group had the same tendency as in the OVX-FSM group, but was not significant. A significant $\mathrm{F}$ ratio in plasma HDL-cholesterol was found by one-way analysis of variance. The plasma HDL-cholesterol in the OVX-FSM and OVX-SM groups was higher than that in the OVX-C and sham-C groups. But Tukey's test could not detect a significance.

The liver total cholesterol contents were significantly lower in the OVX-SM and OVX-FSM groups than in the OVX-C group. The level of fecal bile acid excretion in the OVX-C, OVX-SM, OVX-FSM and sham-C groups was

Table 2. Body weights, food intake, and tissue weight in ovariectomied (OVX) hamsters fed the control, soy milk and fermented soy milk diets, and sham-operated (Sham) hamsters fed the control diet.

\begin{tabular}{lccccc}
\hline & $\begin{array}{c}\text { OVX-C } \\
(n=6)\end{array}$ & $\begin{array}{c}\text { OVX-SM } \\
(n=5)\end{array}$ & $\begin{array}{c}\text { OVX-FSM } \\
(n=6)\end{array}$ & $\begin{array}{c}\text { Sham-C } \\
(n=4)\end{array}$ & ANOVA $(p<)$ \\
\hline Initial body weight $(\mathrm{g})$ & $143 \pm 11$ & $145 \pm 11$ & $143 \pm 7$ & $145 \pm 11$ & NS \\
Final body weight $(\mathrm{g})$ & $180 \pm 6$ & $187 \pm 12$ & $187 \pm 10$ & $176 \pm 17$ & $\mathrm{NS}$ \\
Food intake (g/d) & $8.7 \pm 0.5$ & $9.6 \pm 0.6$ & $9.4 \pm 0.6$ & $9.1 \pm 1.0$ & NS \\
Liver dry weight $(\mathrm{g})$ & $1.86 \pm 0.10$ & $1.96 \pm 0.13$ & $1.83 \pm 0.15$ & $1.84 \pm 0.21$ & NS \\
Uterus weight $(\mathrm{g})$ & $0.15 \pm 0.03^{\mathrm{a}}$ & $0.15 \pm 0.01^{\mathrm{a}}$ & $0.14 \pm 0.03^{\mathrm{a}}$ & $0.55 \pm 0.03^{\mathrm{b}}$ & 0.0001 \\
\hline
\end{tabular}

\footnotetext{
${ }^{\mathrm{ab}}$ Mean values within a row not sharing a common superscript letter were significantly different, $p<0.05$, (Tukey's test).
} 
Table 3. Plasma and liver lipids in ovariectomied (OVX) hamsters fed the control, soy milk and fermented soy milk diets, and Sham-operated (sham) hamsters fed the control diet.

\begin{tabular}{|c|c|c|c|c|c|}
\hline & $\begin{array}{l}\text { OVX-C } \\
(n=6)\end{array}$ & $\begin{array}{c}\text { OVX-SM } \\
(n=5)\end{array}$ & $\begin{array}{l}\text { OVX-FSM } \\
\quad(n=6)\end{array}$ & $\begin{array}{l}\text { Sham-C } \\
(n=4)\end{array}$ & ANOVA $(p<)$ \\
\hline \multicolumn{6}{|l|}{ Plasma lipid } \\
\hline Total cholesterol (mg/dL) & $159 \pm 18$ & $172 \pm 15$ & $161 \pm 7$ & $149 \pm 13$ & NS \\
\hline Triglyceride $(\mathrm{mg} / \mathrm{dL})$ & $232 \pm 40^{\mathrm{a}}$ & $186 \pm 15^{\mathrm{ab}}$ & $180 \pm 20^{\mathrm{b}}$ & $212 \pm 29^{\mathrm{ab}}$ & 0.05 \\
\hline HDL-cholesterol (mg/dL) & $69.6 \pm 13.4$ & $86.0 \pm 7.9$ & $83.2 \pm 5.4$ & $70.4 \pm 8.5$ & 0.05 \\
\hline $\begin{array}{l}\text { VLDL+LDL-cholesterol } \\
\quad(\mathrm{mg} / \mathrm{dL})\end{array}$ & $89.2 \pm 8.8$ & $86.2 \pm 8.5$ & $77.5 \pm 13.7$ & $78.4 \pm 10.5$ & NS \\
\hline Atherogenic index $\$$ & $0.56 \pm 0.05^{\mathrm{a}}$ & $0.50 \pm 0.02^{\mathrm{ab}}$ & $0.48 \pm 0.08^{b}$ & $0.53 \pm 0.04^{\mathrm{ab}}$ & 0.05 \\
\hline \multicolumn{6}{|l|}{ Liver lipid } \\
\hline $\begin{array}{l}\text { Total cholesterol } \\
\text { (mg/g dry weight)* }\end{array}$ & $14.0 \pm 0.7^{\mathrm{a}}$ & $8.0 \pm 0.7^{b}$ & $7.6 \pm 0.7^{b}$ & $10.8 \pm 3.2^{\mathrm{ab}}$ & 0.005 \\
\hline Total cholesterol (mg/liver)* & $25.9 \pm 8.7^{\mathrm{a}}$ & $15.6 \pm 1.2^{\mathrm{b}}$ & $13.9 \pm 1.6^{\mathrm{b}}$ & $19.7 \pm 6.0^{\mathrm{ab}}$ & 0.005 \\
\hline $\begin{array}{l}\text { Triglyceride } \\
\text { (mg/g dry weight) }\end{array}$ & $41.4 \pm 4.2$ & $42.6 \pm 5.2$ & $39.9 \pm 4.2$ & $44.3 \pm 4.2$ & NS \\
\hline Triglyceride (mg/liver) & $76.9 \pm 8.7$ & $83.2 \pm 11.5$ & $73.1 \pm 10.4$ & $81.2 \pm 8.7$ & NS \\
\hline
\end{tabular}

${ }^{\mathrm{ab}}$ Mean values within a row not sharing a common superscript letter were significantly different, $p<0.05$ (Tukey's test).

${ }^{*}$ Means were compared after logarithmic transformation of the data.

${ }^{\$}$ Atherogenic index $=$ VLDL+LDL-cholesterol/HDL-cholesterol.

$0.9 \pm 0.1,3.4 \pm 0.8,4.3 \pm 1.5$, and $1.3 \pm 0.6 \mathrm{mmol} / 3 \mathrm{~d}$. The bile acid excretion of the OVX-SM and OVX-FSM groups was greater than that of the OVX-C and sham-C groups. Studies on rats (17), rabbits (18) and growing hamsters $(8)$ have also shown that soybean protein increases faecal bile acid excretion. The hepatic cholesterol metabolism may change in order to provide more cholesterol for bile acid synthesis (17).

Premenopausal women have a much lower incidence of coronary heart disease than men of a similar age, but after menopause the difference between men and women decreases (19). Stevenson et al. reported that the change from the premenopausal to postmenopausal status causes an increase in total cholesterol, LDLcholesterol and triglyceride, and a reduction in $\mathrm{HDL}_{2}{ }^{-}$ cholesterol (1). In this study using hamsters, there was tendency for higher plasma VLDL+LDL-cholesterol, atherogenic index and liver cholesterol content in ovariectomy, but it was not significant. It is known that ovariectomy induces an increase in serum total cholesterol levels in rats $(7,20)$, rabbits $(21)$ and hamsters (11).

Soy milk fermented by bifidobacterium breve strain Yakult increased the HDL-cholesterol level and decreased the VLDL+LDL-cholesterol level, and consequently decreased the atherogenic index value in growing male hamsters fed a high-fat diet that was cholesterol-free (8). Under the same conditions with a cholesterol-enriched diet, the plasma total cholesterol level was also decreased. The plasma parameter of OVXhamsters in this study was consistent with that of growing male hamsters.

Estrogen injection into OVX rat (20) and rabbit (21) reduced the plasma cholesterol level to below the shamoperated value. Some reports suggest that isoflavone influences the cholesterol-lowering effect of soy due to its estrogen-like action $(22,23)$. But the semipurified extract of soy, rich in isoflavones, added to casein-lactalbumin protein, did not have the same effects as intact soy protein on plasma lipids in ovariectomized cynomolgus monkeys (24).

The cholesterol-lowering effects of lecithin in soy have been observed in animals $(25,26)$ and humans (27) when hyperlipidemia exists. Wilson et al. showed that the cholesterol-lowing efficacy of soy oil was enhanced with the addition of soy lecithin in hamsters (28).

Bifidobacterium breve strain Yakult produces lactic and acetic acid from carbohydrates. Lactic acid delayed the gastric emptying rate and led to reductions in glucose absorption and plasma insulin in a glucose tolerance test in rats (29). Glucose and insulin regulate lipogenic enzyme activities and gene expression (30). These findings may explain why the fermented soy milk induced a greater decrease in plasma triglyceride and atherogenic index than soy milk in the present study.

The 30\% level of soy milk and fermented soy milk in this study was determined from our previous unpublished study. This level of fermented soy milk significantly reduced the atherogenic index in growing male hamsters fed a high-fat cholesterol-free $\operatorname{diet}(8)$.

In conclusion, the present study demonstrated that bifidobacterium-fermented soy milk had a hypolipidemic effect in ovariectomized hamsters.

\section{Acknowledgments}

We wish to thank the staff of our laboratory animal facility for the careful maintenance of the hamsters. We are also grateful to Ms. J. Otsuka for helpful advice regarding the hamster estrous cycle. 


\section{REFERENCES}

1) Stevenson JC, Crook D, Godsland IF. 1993. Influence of age and menopause on serum lipid and lipoproteins in healthy women. Atherosclerosis 98: 83-90.

2) Stampfer MJ, Colditz GA, Wilwtt WC, Manson JE, Rosner B, Speizer FE, Hennekens CH. 1991. Postmenopausal estrogen therapy and cardiovascular disease: ten-year follow-up from the Nurses' Health Study. New Engl J Med 325: 756-762.

3) Mathieson RA, Kitts WD. 1980. Binding of phytoestrogen and the hypothalamus of the ewe. J Endocrinology 85: 317-323.

4) Wang H, Murphy PA. 1994. Isoflavone composition of American and Japanese soybeans in Iowa: effect of variety, crop year, and location. J Agric Food Chem 42: 1674-1677.

5) Ishikawa F, Mizobuchi T, Aiyama R, Yokokura T. Japan Kokai Tokkyo Koho 08-051646.

6) King RA, Broadbent JL, Head RJ. 1996. Absorption and excretion of the soy isoflavone genistein in rats. J Nutr 126: $176-182$.

7) Kikuchi-Hayakawa H, Onodera N, Matsubara S, Yasuda E, Chonan O, Takahashi R, Ishikawa F. 1998. Effects of soy milk and Bifidobacterium fermented soy milk on lipid metabolism in aged ovariectomized rats. Biosci Biotechnol Biochem 62: 1688-1692.

8) Kikuchi-Hayakawa H, Onodera N, Matsubara S, Yasuda E, Shimakawa Y, Ishikawa F. 1998. Effect of soya milk and Bifidobacterium-fermented soya milk on plasma and liver lipids, and faecal steroids in hamsters fed on a cholesterol-free or cholesterol-enriched diet. Brit J Nutr 79: 97-105.

9) Turley SD, Dietschy JM. 1982. Cholesterol metabolism and excretion. In: The Liver: biology and pathobiology (Arias I, Popper H, Schachter, DA, eds), p 467-492. Raven Press, New York.

10) Horton JD, Cuthbert JA, Spady DK. 1995. Regulation of hepatic $7 \alpha$-hydroxylase expression and response to dietary cholesterol in the rats and hamster. J Biol Chem 270: $5381-5387$.

11) Sohn E, Daggy BP, Arjmandi BH. 1999. Ovariectomized hamster: A potential model postmenopausal hypercholesterolemia. J Nutr Biochem 10: 660-663.

12) Association of Official Analytical Chemists. 1990. Official Methods of Analysis, 15th ed. Arlington, VA: AOAC

13) Folch J, Lees M, Sloane-Stanley GH. 1957. A simple method for the isolation and purification of total lipids from animal tissues. J Biol Chem 226: 497-509.

14) Zar JH. 1984. Biostatistical Analysis, p 185-235, Prentice-Hall, Englewood Cliffs, NJ.

15) Wade GN. Some effects of ovarian hormones on food intake and body weight in female rats. J Comp Physiol Psychol 88: 183-193.

16) Jones AP, McElroy JF, Crnic L,Wade GN. 1991. Effects of ovariectomy on thermogenesis in brown adipose tissue and liver in Syrian hamsters. Physiol Behav 50: 41-45.

17) Nagata Y, Ishiwaki N, Sugano M. 1982. Studies on the mechanism of antihypercholesterolemic action of soy protein and soy protein-type amino acid mixtures in relation to the casein counterparts in rats. J Nutr 112 :
1614-1625.

18) Huff MW, Carroll KK. 1980. Effects of dietary protein on turnover oxidation, and absorption of cholesterol, and on steroid excretion in rabbits. $J$ Lipid Res 21: 546-558.

19) Celemajer DS, Sorensen KE, Spiegelhalter DJ, Georgakopulos D, Robinson J,Deanfieeld JE. 1994. Aging is associated with endothelial dysfunction in healthy men years before the age-related deadline in women. J Am Coll Cardiol 24: 471-476.

20) Sato M, Rippy MK, Bryant HU. 1996. Raloxifene, ramoxifen, nafoxidine, or estrogen effects on reproductive and nonreproductive tissues in ovariectomized rats. FASEB J 10: 905-912.

21) Haarbo J, Leth-Espensen $P$, Stender S, Christiansen $C$. 1991. Estrogen monotherapy and combinated estrogen-progestogen replacement therapy attenuate aortic accumulation of cholesterol in ovariectomized cholesterol-fed rabbits. J Clin Invest 87: 1274-1279.

22) Anthony MS, Clarkson TB, Hughes JRCL, Morgan TM, Burk GL. 1996. Soybean isoflavones improve cardiovascular risk factors without affecting the reproductive system of peripubertal Rhesus monkeys. J Nutr 126: 43-50.

23) Potter SM. 1995. Overview of proposed mechanisms for hypocholesterolemic effect of soy. J Nutr 125: 606s611 s.

24) Greaves KA, Parks JS, Williams JK, Wagner JD. 1999. Intact dietary soy protein, but not adding an isoflavonerich soy extract to casein, improves plasma lipids in ovariectomized cynomolgus monkeys. J Nutr 129: 1585-1592.

25) Jimenez MA, Scarino ML, Vignolini F, Mengheri E. 1990. Evidence that polyunsaturated lecithin induces a reduction in plasma cholesterol level and favorable changes in lipoprotein composition in hypercholesterolemic rats. J Nutr 120: 659-667.

26) Hunt CE, Duncan LA. 1985. Hyperlipoproteinaemia and atherosclerosis in rabbits fed low-level cholesterol and lecithin. Br J Exp Pathol 66: 35-46.

27) Childs MT, Bowlin JA, Oglivie JT, Hazzard WR, Albers JJ. 1981. The contrasting effects of a dietary soya lecithin product and corn oil on lipoprotein lipids in normolipidemic and familial hypercholesterolemic subjects. Atherosclerosis 38: 217-222.

28) Wilson TA, Meservey CM, Nicolosi RJ. 1998. Soy lecithin reduced plasma lipoprotein cholesterol and early atherogenesis in hypercholesterolemic monkeys and hamsters: beyond linoleate. Atherosclerosis 140: 147-153.

29) Ebihara K. 1996. Effect of lactic acid in postrandial plasma-glucose and -insulin response in rats administered glucose solution. Nutr Res 16: 1576-1585.

30) Iritani N. 1992. Nutritional and hormonal regulation of lipogenic-enzyme gene expression in rat liver. Eur J Biochem 205: 433-442.

31) American Institute of Nutrition. 1977. Reports of the American Institute of Nutrition Ad Hoc Committee on standards for nutritional studies. J Nutr 107: 13401348. 